\title{
Review Article \\ Efficacy and Safety of Pomegranate Medicinal Products for Cancer
}

\author{
Christian Vlachojannis, ${ }^{1}$ Benno F. Zimmermann, ${ }^{2,3}$ and Sigrun Chrubasik-Hausmann ${ }^{1}$ \\ ${ }^{1}$ Institute of Forensic Medicine, University of Freiburg, Albertstr. 9, 79104 Freiburg, Germany \\ ${ }^{2}$ Institute of Nutrition and Food Sciences, Food Technology and Food Biotechnology, University of Bonn, \\ Römerstraße 164, 53117 Bonn, Germany \\ ${ }^{3}$ Institut Prof. Dr. Georg Kurz GmbH, Eupener Straße 161, 50933 Köln, Germany
}

Correspondence should be addressed to Sigrun Chrubasik-Hausmann; sigrun.chrubasik@klinikum.uni-freiburg.de

Received 25 February 2014; Revised 8 July 2014; Accepted 2 September 2014

Academic Editor: Junhua Zhang

Copyright (C 2015 Christian Vlachojannis et al. This is an open access article distributed under the Creative Commons Attribution License, which permits unrestricted use, distribution, and reproduction in any medium, provided the original work is properly cited.

Preclinical in vitro and in vivo studies demonstrate potent effects of pomegranate preparations in cancer cell lines and animal models with chemically induced cancers. We have carried out one systematic review of the effectiveness of pomegranate products in the treatment of cancer and another on their safety. The PubMed search provided 162 references for pomegranate and cancer and 122 references for pomegranate and safety/toxicity. We identified 4 clinical studies investigating 3 pomegranate products, of which one was inappropriate because of the low polyphenol content. The evidence of clinical effectiveness was poor because the quality of the studies was poor. Although there is no concern over safety with the doses used in the clinical studies, pomegranate preparations may be harmful by inducing synthetic drug metabolism through activation of liver enzymes. We have analysed various pomegranate products for their content of anthocyanins, punicalagin, and ellagic acid in order to compare them with the benchmark doses from published data. If the amount of coactive constituents is not declared, patients risk not benefiting from the putative pomegranate effects. Moreover, pomegranate end products are affected by many determinants. Their declaration should be incorporated into the regulatory guidance and controlled before pomegranate products enter the market.

\section{Introduction}

Pomegranate products are amongst most promising antitumorigenic dietary supplements. The polyphenol fraction of pomegranate exerts antiproliferative and proapoptotic effects in a number of cancer cell lines [1]. Various mediators of carcinogenesis are inhibited by the pomegranate active principle in vitro, for example, vascular endothelial growth factor [2], insulin-like growth factors [3], cytokinestimulated NF- $\kappa \mathrm{B}[4]$, and others $[5,6]$. Fermentation is a new technology that enriches coactive compounds [7]. Fermentation of pomegranate juice with Lactobacillus plantarum increased the concentration of ellagic acid and enhanced the antimicrobial activity of the juice. Both fresh and fermented juices inhibited the growth of K562 tumor cells [7]. Polyphenols from fermented pomegranate juice showed about twice the antiproliferative effect shown by polyphenols from fresh pomegranate juice. They also inhibited the activity of aromatase and 17- $\beta$-hydroxysteroid dehydrogenase type 1 by $60-80 \%$ and inhibited chemically induced formation of cancerous lesions in a murine mammary gland organ culture by about $50 \%$ [8] However, a specific purified polyphenol compound and pomegranate seed oil were more effective than fermented juice in this in vitro test [9]. The isolated ellagitannins, punicalagin, and ellagic acid also had a high antiproliferative activity against various cancer cell lines $[10$, 11].

The aromatase enzyme, which converts androgen to estrogen, plays a key role in breast cancer. Tamoxifen is the usual antiestrogen therapy for hormone-receptor-positive breast cancer in premenopausal women, though it carries a risk of development of resistance [12]. Pomegranate fruit 
extracts enhanced the action of tamoxifen in both tamoxifensensitive and tamoxifenresistant breast cancer cells, through the inhibition of cell viability by inducing the cell-death machinery [13].

The polyphenols also inhibited the expression of genes for key androgen-synthesizing enzymes and androgen receptors, suggesting that the pomegranate polyphenols (mainly the oligomeric punicalagin and the monomeric ellagic acid) affect androgen-independent prostate cancer cells and the subset of human prostate cancer cells where the androgen receptor is upregulated $[4,14]$. In investigations of the antiinvasive effects of ellagic acid in androgen-independent human and rat prostate cancer cell lines in vitro, ellagic acid significantly inhibited the motility and invasion of cells examined in migration and invasion assays. The secretion of matrix metalloproteinases from androgen-independent human and rat prostate cancer cell lines and the proteolytic activity of collagenase/gelatinase were significantly reduced, indicating that the anti-invasive potential of prostate cancer cells is mediated via protease activity [15].

Although all pomegranate-derived materials contribute to a greater or lesser extent to the anticancer effect of pomegranate, the polyphenol fraction and supercritical $\mathrm{CO}_{2}-$ extracted seed oil were more potent than cold-pressed pomegranate seed oil in inhibiting growth of prostate cancer xenografts in athymic mice [16]. Pomegranate juice was more effective than compounds isolated from the juice [17].

In immunodeficient mice, pomegranate juice and extract inhibited tumor-associated angiogenesis and slowed the growth of prostate cancer [18]. Oral infusion of pomegranate fruit extract resulted not only in a dose-dependent inhibition of tumor growth, but also in a decrease of prostate-specific antigen (PSA) levels in mice implanted with androgenresponsive cancer cells [19]. Tumor reductions were also seen in mice with induced lung, colon, and skin cancers [1].

Of the polyphenols, the chemopreventive pomegranate ellagitannins (e.g., punicalagin and punicalin) are metabolized during absorption. One of the metabolites, ellagic acid, is further metabolized by the colonic microflora to urolithin A. Both ellagic acid and urolithin A contribute to the mechanism of anticancer action, but urolithin was less effective in inhibiting cancer cell proliferation [20-22]. There was no difference in metabolite production between pomegranate juice and extracts thereof [23], though inactive ellagitannin-derived metabolites are also produced by the colonic microflora [24]. This may account for individual differences in the response to pomegranate consumption.

The aim of this study was to summarize data on the clinical effectiveness and safety of pomegranate preparations for the treatment of cancer and to analyse various pomegranate preparations for their content of coactive compounds in order to find out the dose required for an anticancer effect in patients suffering from prostate cancer.

\section{Methods}

2.1. Systematic Reviews on Effectiveness and Safety. On June 20, 2014 we searched PubMed using the terms: "pomegranate cancer" and "pomegranate prostate" and, on June 29, "pomegranate safety" and "pomegranate toxicity," the reference lists of articles were searched by hand for other publications. No methodological filter was applied and the search was not limited by language. The full manuscript was retrieved for each record that had a chance of meeting the review criteria (clinical trial, safety investigation). Two authors (Christian Vlachojannis and Sigrun ChrubasikHausmann) extracted the data independently and evaluated the quality of the studies and the strength of the evidence of clinical effectiveness using the same criteria as in previous reviews [25-35]. Briefly, the assessment of quality was based on "yes" or "no" answers to the following questions: was or were

(i) patients included on the basis of specified eligibility criteria;

(ii) randomization appropriate;

(iii) treatment allocation concealed;

(iv) baseline values of the groups similar

(v) outcome measures and control interventions explicitly described;

(vi) cointerventions comparable;

(vii) outcome measures relevant;

(viii) adverse events fully described;

(ix) attrition of patients from the study (the "drop-outs") fully described;

(x) sample size based on a priori power calculation;

(xi) analysis by intention-to-treat in the event of attrition of patients during the study;

(xii) point estimates and measures of variability presented for the primary outcome measure;

(xiii) studies undertaken over an appropriate time-course to demonstrate the putative effect.

For observational studies, some of the questions are not applicable but the inability to supply a "yes" answer itself marks an "absence of quality" in systematic reviews of this sort. Potential disagreements were discussed and resolved by referring to the original protocol.

Adding up the "yes" answers applicable to each study gave it a total score (TS) out of a maximum of 13. Evidence of effectiveness was defined as (i) "strong": pooling of data from at least 2 confirmatory studies demonstrating a clinically relevant effect;

(ii) "moderate": consistent findings from one confirmatory study with a clinically relevant effect, multiple exploratory studies of high internal validity (TS 10 and higher), or both;

(iii) poor: multiple exploratory studies of low internal validity or one single study of high internal validity. 


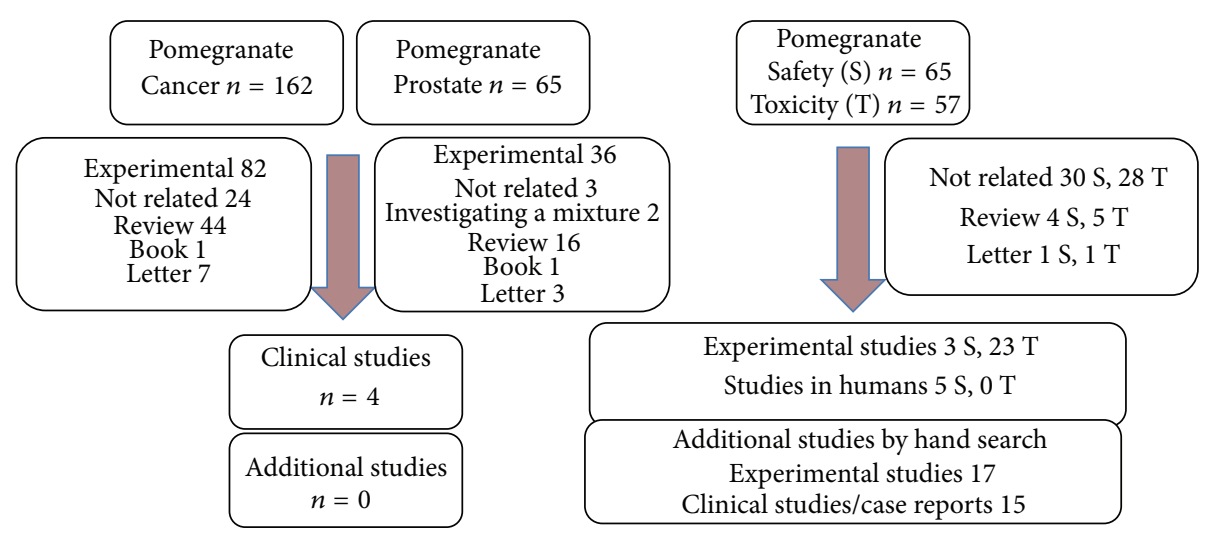

FIGURE 1: Search profile.

2.2. Analyses of Various Pomegranate Products. The pomegranate preparations we investigated included

(A) three commercially available pure (100\%) juices:

(i) 5174-13, expiry date June 2, 2015,

(ii) L3074, expiry date Sept 15, 2014,

(iii) POM Wonderful (expiry date April 21, 2014);

(B) two juice concentrates:

(iv) POM Wonderful expiry date August 1, 2014

(v) F4, a commercially available fermented pomegranate concentrate supplemented with $10 \%$ elderberry concentrate (details not stated; photometric assessment on May 30, 2013);

(C) five extracts:

(vi) POMx capsules (1000 mg capsules, expiry date June 17, 2015),

(vii) ultra Granatapfel forte capsules (500 mg, expiry date Sept., 2015),

(viii) extract 20651 (not commercially available, batch 19829, native drug extract ratio 5.3-8:1, solvent ethanol),

(ix) GranaProstan capsules (500 mg freeze-dried powder from fermented pomegranate juice (84\%),

(x) pomegranate extract $(16 \%$, drug extract ratio and solvent not stated, photometric assessment in February 2013, expiry date Feb 18, 2015).

Punicalagins $\mathrm{A}$ and $\mathrm{B}$ and ellagic acid were analysed by RP-UHPLC-UV using authentic reference compounds. Anthocyanidins were analysed by RP-UHPLC-Vis using cyanidin-3-O-glycoside as reference. Total polyphenols were determined by the Folin-Ciocalteu photometric method using gallic acid as reference. Details of the methods are presented at http://www.uniklinik-freiburg.de/ rechtsmedizin/forschung/phytomedizin.html.

\section{Results}

3.1. Systematic Reviews on Effectiveness and Safety. We identified 162 references for "pomegranate cancer" and 65 references for "pomegranate prostate," both included 4 clinical studies investigating pomegranate products in prostate cancer patients (Figure 1, see webpage: PubMed searches). The quality of the studies is listed in Table 1. According to the criteria set out above in the methods, the evidence of effectiveness of pomegranate products for the treatment of prostate cancer is poor.

We identified 42 references for "pomegranate safety" and 57 for "pomegranate toxicity," respectively. A total of 26 experimental and 5 clinical studies were included in the part on safety together with 17 experimental studies and 15 clinical studies from hand searches (Figure 1, see webpage: PubMed searches).

3.2. Analyses of Various Pomegranate Products. Table 2 summarizes the total polyphenol content by photometric assessment (Folin-Ciocalteu method) as declared by the manufacturers, along with our own Folin-Ciocalteu data. The HPLC chromatograms are placed on the above-mentioned webpage (see Results). The table also summarizes coactive compounds as assessed by HPLC and their sum in $\mathrm{mg} / \mathrm{L}$ or $\mathrm{mg} / \mathrm{kg}$ and the daily dose of polyphenols in the doses of product recommended by the manufacturers. It can be seen that the sum of our HPLC measurements of anthocyanins, punicalagins, and ellagic acid is substantially less than the photometrically measured total polyphenols, though there is a correlation of sorts.

The lower part of the table shows the content on coactive compounds in commercially available pomegranate preparations, as taken from the references stated and the calculated sum of polyphenols in the recommended daily doses.

Table 3 lists the individual anthocyanidins measured by HPLC, which also allows a distinction to be made between pomegranate and elderberry anthocyanidins in the juice concentrate F4. 
TABLE 1: Quality criteria considered in the 4 trials investigating pomegranate products.

\begin{tabular}{|c|c|c|c|c|}
\hline & $\begin{array}{l}\text { Clin cancer Res } \\
\text { 2006; 12: 4018-26 } \\
\text { Pantuck et al. [36] }\end{array}$ & $\begin{array}{l}\text { Prostate cancer prostatic Dis } \\
\text { 2013; } 16: 50-5 \\
\text { Paller et al. [37] }\end{array}$ & $\begin{array}{l}\text { J cancer } \\
\text { 2013; 4: 597-605 } \\
\text { Stenner-Liewen et al. [40] }\end{array}$ & $\begin{array}{l}\text { Cancer prev Res (Phila) } \\
\text { 2013; 6: 1120-7 } \\
\text { Freedland et al. [38] }\end{array}$ \\
\hline & $N=46$ & $N=92$ & $N=97$ & $N=69$ \\
\hline SM & Juice POM wonderful & extract POMx & Pomegranate blend & Extract POMx \\
\hline Dose & $240 \mathrm{~mL} /$ day & $1000 \mathrm{mg}$ versus $2000 \mathrm{mg} /$ day & $500 \mathrm{~mL} /$ day & $2 \times 1000 \mathrm{mg} /$ day \\
\hline pa & $570 \mathrm{mg} /$ day & Not stated & $700 \mathrm{mg} /$ day $^{*}$ & $1200 \mathrm{mg} /$ day \\
\hline \multirow[t]{2}{*}{ cai } & Not stated ${ }^{*}$ & $400 \mathrm{mg}$ versus $800 \mathrm{mg} /$ day & $40 \mathrm{mg} /$ day & Not stated $^{*}$ \\
\hline & Open, uncontrolled & Low dose (45), high dose (47) & Placebo (48), control (49) & Placebo (36), control (33) \\
\hline $\mathrm{D}$ & 13 months & Up to 18 months & 4 weeks & 4 weeks \\
\hline $\mathrm{R}$ & $\begin{array}{l}\text { Lengthening of PSA } \\
\text { doubling time }\end{array}$ & $\begin{array}{l}\text { No difference between groups } \\
\text { lengthening of PSA doubling time }\end{array}$ & $\begin{array}{l}\text { No difference between } \\
\text { groups }\end{array}$ & $\begin{array}{l}\text { No difference between } \\
\text { groups }\end{array}$ \\
\hline A & Prostate cancer & Prostate cancer & Prostate cancer & $\begin{array}{l}\text { Prostate cancer requiring } \\
\text { Radical prostatectomy }\end{array}$ \\
\hline B & Not applicable & Not stated & Yes & Yes \\
\hline $\mathrm{C}$ & Not applicable & Not stated & Yes & Yes \\
\hline $\mathrm{E}$ & Not applicable & Not stated & Yes & Yes \\
\hline $\mathrm{F}$ & Not applicable & Yes & Yes & Yes \\
\hline G & Not applicable & Yes & Yes & Yes \\
\hline $\mathrm{H}$ & Yes & Yes & Yes & Yes \\
\hline I & Yes & Yes & Yes & Not stated \\
\hline $\mathrm{J}$ & Yes & Yes & Yes & Yes (none) \\
\hline $\mathbf{K}$ & Yes & Yes & Yes & Yes \\
\hline $\mathrm{L}$ & No & Yes & No & No \\
\hline $\mathrm{N}$ & No & No & No & No \\
\hline $\mathrm{O}$ & Yes & Yes & No & No \\
\hline \multirow[t]{2}{*}{ TS } & 6 & 9 & 10 & 9 \\
\hline & $\begin{array}{l}{ }^{*} \text { according to Paller the } \\
\text { same as in extract POMx }\end{array}$ & $\begin{array}{l}{ }^{*} \text { from other source see Hong et al., } \\
2008[14]\end{array}$ & $\begin{array}{l}{ }^{*} \text { see Chrubasik-Hausmann } \\
\text { et al. 2014a [41] }\end{array}$ & ${ }^{*}$ no details given on request \\
\hline
\end{tabular}

SM study medication, pa photometrically assessed, cai coactive ingredients/day (HPLC), D duration of treatment, R result.

Quality criteria A: eligibility criteria specified, B: randomization appropriate, C: treatment allocation concealed, E: similarity at baseline, F: outcome measures and control interventions explicitly described, G: cointerventions comparable, H: outcome measures relevant, I: adverse events and J drop-outs fully described, K: sample size based on a priori power calculation, L: intention-to-treat analysis, N: point estimates and measures of variability presented for the primary outcome measure, and O: appropriate timing giving a total score (TS) of 13.

\section{Discussion}

4.1. Evidence of Effectiveness of Pomegranate Products. Pomegranate preparations have so far been investigated only in patients with prostate cancer. In an uncontrolled study, patients with rising PSA after surgery or radiation for prostate cancer were treated with $240 \mathrm{~mL}$ of fermented pomegranate juice per day, containing total polyphenols equivalent to $570 \mathrm{mg}$ of gallic acid [36]. The content of coactive compounds as assessed by HPLC was not stated but was said in another study [37] to be similar to that in extract POMx, which contained $370 \mathrm{mg}$ punicalagin and $30 \mathrm{mg}$ ellagic acid in the daily dosage [14]. Mean PSA doubling time increased with treatment from a mean of 15 months at baseline to 54 months after treatment [36]. The remaining observational study included 104 men with rising PSA but without metastases. Daily doses of either 1000 or $3000 \mathrm{mg}$ of a polyphenol extract of pomegranate were given (POMx, 37\% punicalin (POM Wonderful, LLC; Los Angeles, California, http://cms.herbalgram.org/herbclip/474/051321-474.html.

Patients were stratified according to their baseline PSA doubling time and Gleason score. The primary endpoint was the increase in PSA doubling time after 6 months. The average PSA doubling time did indeed increase from 12 months to almost 19 months, irrespective of dose. This may or may not indicate a ceiling effect. The data are not conclusive because of the lack of a placebo and the unreliability of the endpoint [37]. The coactive compound urolithin A was detected more often in benign and malignant prostate tissue in patients who had received POMx during the 4 weeks before surgery. An inverse correlation was expected between intraprostatic urolithin A and the oxidative stress tissue marker 8-hydroxy$2^{\prime}$-deoxyguanosine content. The study was powered to detect a $35 \%$ reduction in that marker. However, POMx was 


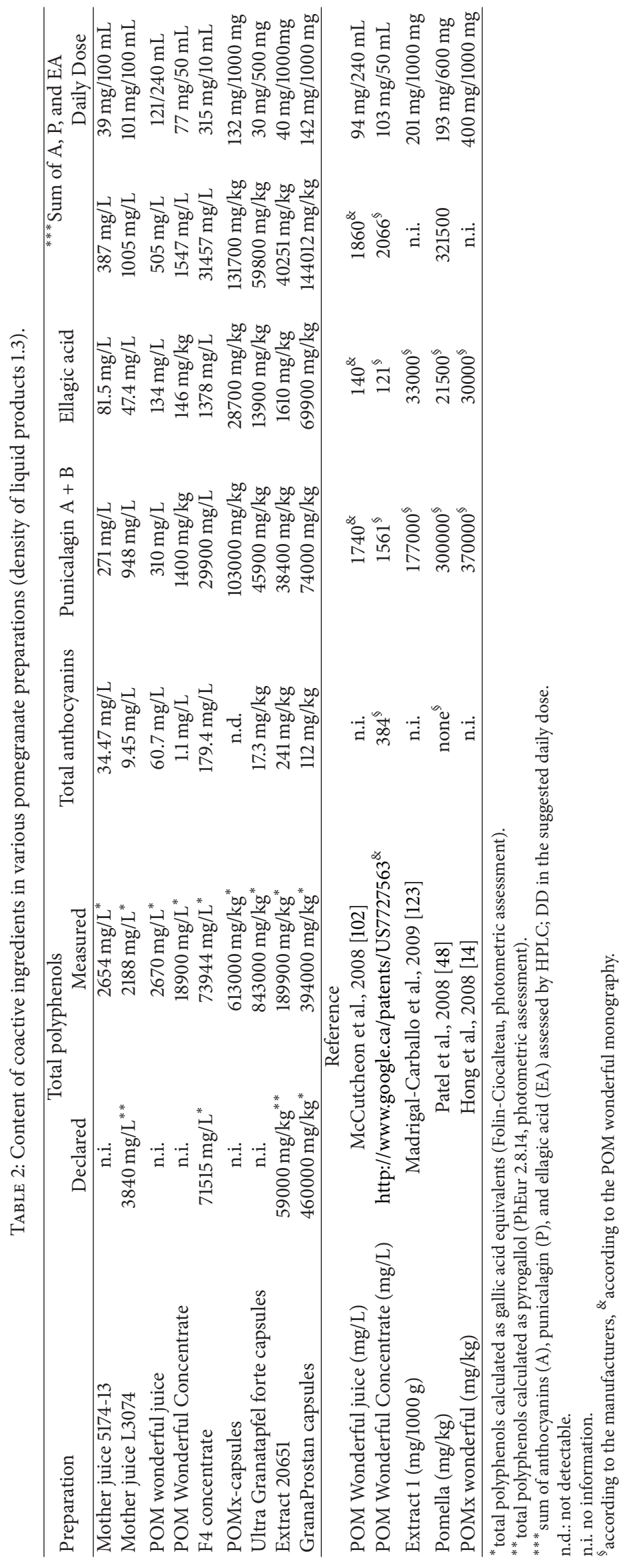




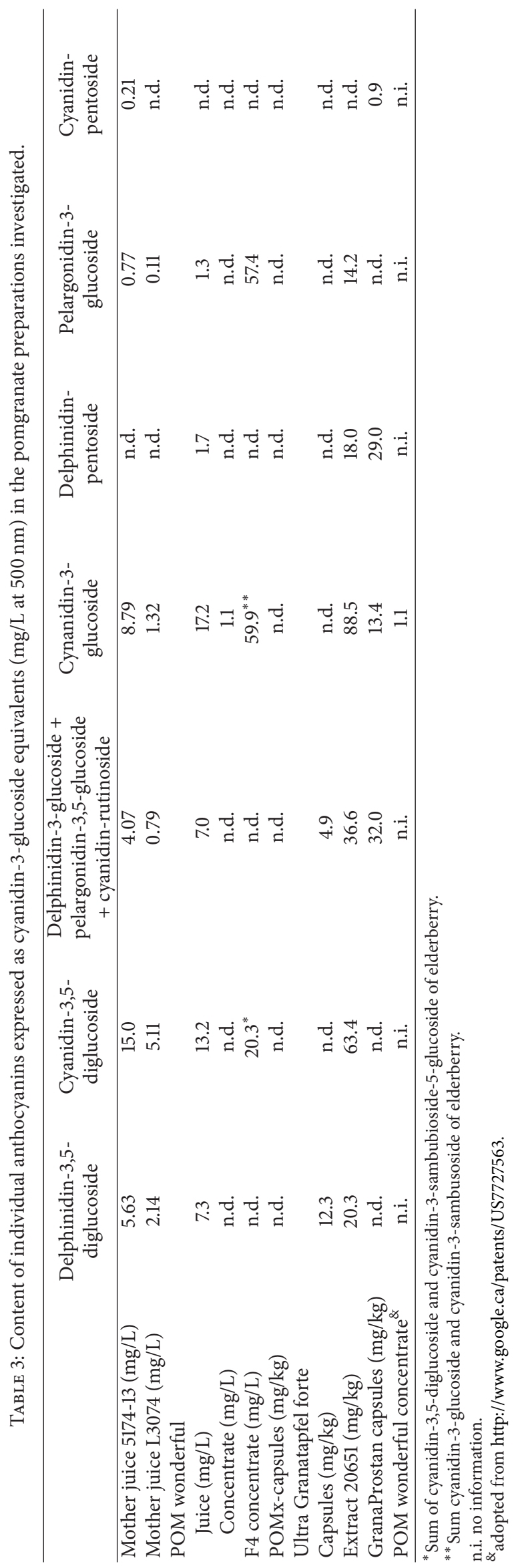


associated only with $16 \%$ lowermarker content, which was not statistically significant in this short-term clinical trial [38]. It may well be that the 4 -week treatment duration was too short. The results are eagerly awaited of two on-going and two as yet unpublished investigations of pomegranate in prostate cancer patients with a juice, a proprietary extract (2 studies) and a liquid extract [39]. Stenner-Liewen et al. [40] carried out a phase IIb, double-blinded, randomized placebo-controlled trial in patients with histologically confirmed prostate cancer in patients with a PSA $\geq 5 \mathrm{ng} / \mathrm{mL}$; this used an amount of pomegranate active principle per day (20 mg in $500 \mathrm{~mL}$ ), which was only $5 \%$ of that investigated in the other studies [41]. Unsurprisingly, the study concluded that daily pomegranate intake has no impact on PSA levels in patients with advanced prostate cancer.

In our critique of the Cochrane reviews on herbal medicines [42], we called for rigorous declaration of coactive ingredients in study medications to avoid misleading interpretations of data. For example, Stenner-Liewen and coworkers [40] relied on photometric assessments of the coactive principle in their study medication, failing to take into account the fact that photometric assessments overestimate the true polyphenol content by detecting all polyphenolic or antioxidative compounds regardless of their clinical activity [41]. The photometric assessment of the total mixed polyphenols in $500 \mathrm{~mL}$ of the proprietary pomegranate blend was $1147 \mathrm{mg}$ of gallic acid equivalents. Subtracting the various polyphenols from other components of the blend (white tea and chokeberry-agave concentrate does not contain polyphenols) amounted to $445 \mathrm{mg} / 500 \mathrm{~mL}$; the remaining value of around $700 \mathrm{mg}$ of pomegranate polyphenols does not reflect the dose of coactive compounds (e.g., punicalagin and ellagic acid), our HPLC analysis resulted in a total of $20 \mathrm{mg}$. Bench-mark doses of coactive ingredients are given in the study by Paller and coworkers [37], a total of $400 \mathrm{mg}$ per day as assessed by HPLC. Thus the conclusion of the StennerLiewen group that daily pomegranate intake has no impact on PSA levels in patients with advanced prostate cancer is wrong since it was based on an inadequate amount of coactive ingredients in their pomegranate mixture. Likewise, similar confusion exists for cranberry products in which the photometric assessments do not reflect the true content of coactive ingredients [43]. HPLC assessments provided bench-mark doses for the prevention of urinary tract infections [44].

Recently, a significant decrease in PSA levels during treatment with pomegranate extract Pomella (225 mg/kg, Table 2) has been demonstrated in a mouse model of prostate cancer. The production of testosterone, DHT, DHEA, androstenedione, androsterone, and pregnenolone was inhibited in prostate cancer cell lines and serum steroids reduced after 20 weeks of treatment $(0.17 \mathrm{~g} / \mathrm{L}$ in drinking water $)$ [45]. In metastatic castration-resistant PCa cells, POMx exhibited potent in vitro cytotoxicity and in athymic nude mice, the extract retarded C4-2 tumor growth in skeleton and significantly enhanced the efficacy of docetaxel [46]. These studies and the experiments mentioned in the Introduction of our manuscript suggest that the clinical effectiveness of pomegranate products in the treatment of prostate and other cancers deserves further evaluation.

\section{Safety Aspects}

5.1. Based on Experiments. A diet containing 6\% punicalagin given to rats for 37 days caused no obvious toxicity [47]. The oral $\mathrm{LD}_{50}$ of a pomegranate extract standardized to $30 \%$ punicalagins, $5 \%$ ellagic acid, and $0.3 \%$ gallic acid (photometric assessment $70 \%$ polyphenols, trade name POMELLA) was found to be greater than $5 \mathrm{~g} / \mathrm{kg}$ body weight in rats and mice. The respective intraperitoneal $\mathrm{LD}_{50} \mathrm{~s}$ in rats and mice were determined as 217 and $187 \mathrm{mg} / \mathrm{kg}$ body weight. In a subchronic study in rats, a diet containing up to $600 \mathrm{mg} / \mathrm{kg}$ body weight/day of this extract was given over 90 days with or without a 28-day recovery phase. Compared with the control group, giving the extract did not result in any clinically relevant treatment-related organ changes. The "no observed-adverse-effect level" was defined as $600 \mathrm{mg} / \mathrm{kg}$ body weight/day, the highest extract dose tested [48].

Pomegranate fruit extract exerted an embryoprotective effect against adriamycin-induced oxidative stress in 12-day old chick embryos. After 24 and $48 \mathrm{~h}$ of incubation, $70 \mu \mathrm{g} / \mathrm{egg}$ of adriamycin on its own produced a significant dose versus time-dependent reduction in body weight and volume of amniotic fluid and a dose-related increase in gross embryological deformities and significant changes in the levels of biochemical markers in amniotic fluid. These changes were significantly reduced by preadministration of pomegranate fruit extract at a dose of $200 \mu \mathrm{g} / \mathrm{egg}$ [49]. Lead acetate administration inhibited spermatogenesis in rats by reducing the length of the stages related to spermiation and onset of mitosis. The epididymal sperm number and daily sperm production were reduced. Giving ethanolic pomegranate extract along with the lead acetate resulted in longer spermiation stages than with the lead acetate only. The deleterious effects on epididymal sperm number and daily sperm production were reduced. Thus, pomegranate may prevent lead acetateinduced spermatogenic disruption in rats possibly owing to antioxidant effects [50]. Pomegranate also reduced the RNA-damaging effect of doxorubicin, $\mathrm{H}_{2} \mathrm{O}_{2}$, and spermine. Its inhibitory activity could be related to its ability to form complexes with doxorubicin and $\mathrm{H}_{2} \mathrm{O}_{2}$ or its interaction with the intracellular formation of reactive substances that mediated their toxicity [51]. In adult Wistar rats, pomegranate juice augmented the antioxidant defence mechanism against carbon tetrachloride-induced reproductive toxicity [52]. In other tests, pomegranate extract was found to be protective against methotrexate-induced oxidative bone marrow damage [53], reduced methotrexate-induced neurotoxicity [54], and reversed methotrexate-induced oxidative stress and apoptosis in hepatocytes by modulating Nrf2-NF- $\kappa \mathrm{B}$ pathways in male Swiss albino rats. Preparations of pomegranate may, thus, help to reduce some adverse effects of methotrexate. Further tests demonstrated that pomegranate methanolic peel extract inhibited aluminum-induced hepatorenal toxicity [55], mercuric chloride-induced oxidant toxicity [56] and gentamicin-induced nephrotoxicity [57]. Pomegranate seed oil in doses up to $0.64 \mathrm{mg} / \mathrm{kg}$, one hour before $100 \mathrm{mg} / \mathrm{kg}$ of the nephrotoxic agent diazinon had a nephroprotective effect [58]. This has been confirmed with hexachlorobutadiene as the nephrotoxic agent [59]. The "no observable adverse effect 
level" (NOAEL) of pomegranate seed oil was $50.000 \mathrm{ppm}$ PSO (=4.3 g PSO/kg body weight/day) [60].

In hepatitis induced in rats by D-galactosamine/ lipopolysaccharide, a 2 -week pretreatment with pomegranate juice $20 \mathrm{~mL} / \mathrm{kg}$ body weight per day protected against hepatic damage by suppressing oxidative stress. Histopathology showed that the pomegranate juice restored the hepatic architecture to normal [61]. Histopathological studies of the liver of rats fed pomegranate fruit extract and carbon tetrachloride also indicated a hepatoprotective effect. Likewise, pomegranate juice protected against carbon tetrachloride-induced hepatotoxicity [62] and nephrotoxicity [63] and protected against ethylene glycolinduced crystal deposition in renal tubules [64] and the development of azoxymethane-induced aberrant crypt foci [65]. Oral pomegranate extract had a protective effect against cisplatin ototoxicity in rats. Cisplatin ototoxicity was assessed by analysing "distortion product otoacoustic emissions" 3 days before and after the cisplatin injections. Histological changes in the cochleas were observed by light microscopy [66]. This was confirmed in an experimental study with aminoglycoside as the ototoxic agent [67] A whole fruit extract of pomegranate was cardioprotective against doxorubicin-induced toxicity [68].

In the chick embryo model, doses of whole fruit extract (DER 3:1, solvent ethanol 50\%) of less than $0.1 \mathrm{mg}$ per embryo were not toxic. The $\mathrm{LD}_{50}$ of the extract, determined after intraperitoneal administration in mice, was $731 \mathrm{mg} / \mathrm{kg}$ (confidence limits $565-945 \mathrm{mg} / \mathrm{kg}$ ). At the doses of 0.4 and $1.2 \mathrm{mg} / \mathrm{kg}$ of extract, repeated intranasal administration to Wistar rats produced no toxic effects in terms of food intake, weight gain, behavioural or biochemical measurables, nor was it associated with histopathological changes [69]. Aqueous and lipophilic pomegranate peel extracts have demonstrated a dose-dependent antimutagenic activity in Salmonella typhimurium strains [70]; this was probably attributable to the content on ellagitannins [71]. No toxic effects were observed in mice treated with aqueous pomegranate fruit extracts [72]. A study in Swiss mice treated with ethanolic extracts of pomegranate leaf or fruit confirmed the absence of mutagenic effects and the dose-dependent protective effects against cyclophosphamide-induced oxidative DNA damage [73]. However, a later study was carried out on the genotoxicity of whole pomegranate fruit extract (solvent $50 \%$ ethanol) using different in vitro and in vivo assays to detect DNA damage at different expression levels: it indicated that this extract can induce genetic damage at different expression levels: recombinogenic, mutagenic, and clastogenic [74]. Thus, the use of this extract may well carry a genetic risk and an analysis of the balance of risk and benefit is probably crucial. Whereas pomegranate bark [75] and root [76] contain toxic alkaloids, the presence of alkaloids in peel was considered equivocal [77]. Studies of cytotoxicity affecting the Caco-2 cell line and human peripheral blood mononuclear cells (PBMC) could provide preliminary information about toxicity on intestinal cancer cells and normal cells. The effective dose of pomegranate peel extract for stimulating proliferation in Caco-2 cells was $4.7 \mu \mathrm{g} / \mathrm{mL}$ and for PBMCs $44.4 \mu \mathrm{g} / \mathrm{mL}$ [78]. One should therefore be cautious about using peel extract in humans as a natural dietary antioxidant or a therapy (http://archive.lib.cmu.ac.th/full/T/ 2008/pha0808st_ch4.pdf). However, one should also note that the toxic effects of pomegranate fruit extract occurred at higher doses than the doses used either those in animal experiments or in Cuban folk medicine [69].

5.2. Based on Data from Humans. In the clinical study investigating a pomegranate extract in doses of 1000 and $3000 \mathrm{mg}$, diarrhea occurred more often in the high dose group [37]. Heber et al. [79] carried out two clinical pilot studies on the safety of a pomegranate ellagitannin-enriched polyphenol extract. Sixty-four overweight individuals took one, two, or three $710 \mathrm{mg}$ capsules per day of pomegranate extract for 28 days, each capsule containing $435 \mathrm{mg}$ of gallic acid equivalents (GAEs). In none of the subjects were there any serious adverse events on complete blood count, blood chemistry, and urinalysis. In another 22 overweight subjects, levels of thiobarbituric acid reactive substances (TBARS) were significantly less after receiving $1000 \mathrm{mg}$ pomegranate extract (610 mg of GAEs) versus baseline measurements. Diabetic indicators were not worsened in diabetic patients taking pomegranate juice; serum lipid peroxidases were reduced by $56 \%$ and TBSARs by $24 \%$ whereas serum SH groups increased by $12 \%$ and paraoxonase activity by $24 \%$ [80]. In other clinical studies, consumption of pomegranate juice or extracts were also well tolerated [36, 38, 40, 8185]. No toxic effects were seen in a one-year pilot study of the proprietary pomegranate extract POMx in 10 patients with carotid artery stenosis ( 5 of whom continued taking the extract another 2 years) [86]. Interestingly, the improvement in clinical signs took place during the first 12 months of the study but was maintained over the following 2 years. Pomegranate fruit and peel extracts have so far been used safely from a toxicological perspective [87].

Allergies to pomegranate may occur but are very rare [8892]. One case report described exercise-induced anaphylaxis triggered by the ingestion of pomegranate, the allergy being confirmed by immunoblotting and absence of lipid transfer protein cross-reactivity, although exercise-induced anaphylaxis is generally independent of the kind of food ingested before exercise [93]. Mannitol which is also contained in pomegranate has been identified as causing IgE-mediated hypersensitivity [94].

5.3. Risk of Interactions. If pomegranate preparations are taken over longer periods, putative interactions with other medications need to be considered. This is because the pomegranate active principle interacts with hepatic cytochrome P450 $[95,96]$. The in vitro $1^{\prime}$-hydroxylase activity of midazolam, catalysed by human CYP3A, was inhibited less by a commercial pomegranate juice than by the juices from grapefruit, black mulberry, and wild grape [97]. Pomegranate juice did not impair the clearance of oral or intravenous midazolam in volunteers, [98]. However, rhabdomyolysis has been associated with pomegranate juice consumption in a patient taking synthetic rosuvastatin, though the latter is not known to be metabolized by hepatic P450 3A4 [99]. More 
studies are needed to determine whether these and other interactions such as the interaction between pomegranatecontaining products and the immunosuppressive agent tacrolimus [100] are clinically significant [101].

5.4. Analyses of Various Pomegranate Products. The review of the literature indicates that the active principle of pomegranate may well have a potent anticancer potential, but the clinical evidence of effectiveness is still poor because of the poor quality of the available clinical studies. (The results of four further studies are awaited.) Hong and coworkers described the POMx extract as containing monomeric and oligomeric ellagitannins (punicalagin $37-40 \%$ and 3.4\% free ellagic acid) but no anthocyanins as determined by high performance-liquid chromatography. Thus, a dose of $1000 \mathrm{mg}$ of extract contained $400 \mathrm{mg}$ of both ellagitannins. Paller et al. [37] stated that each POMx capsule contained $1000 \mathrm{mg}$ of polyphenol extract, comparable to about $8 \mathrm{oz}$ (about $240 \mathrm{~mL}$ ) of pomegranate juice. According to the "POM wonderful pomegranate juice monograph" of the American Botanical Council [102], the juice contained $1.74 \mathrm{mg} / \mathrm{mL}$ punicalagin and $0.14 \mathrm{mg} / \mathrm{mL}$ ellagic acid, a dose of $94 \mathrm{mg}$ all together in $240 \mathrm{~mL}$. According to the voice message from the company (see webpage: voice message) one POMx pill contained $370 \mathrm{mg}$ punicalagin. This dose has also been mentioned in the review by Kroeger et al. [39]. But according to our measurements, POMx capsules contained only $132 \mathrm{mg}$ of punicalagin and ellagic acid (combined). Since $3000 \mathrm{mg}$ have not been more effective than $1000 \mathrm{mg}$, the optimum dose until a ceiling effect occurs may be in between these doses (1000 and $3000 \mathrm{mg}$ ) or the ceiling effect may even occur at a dose less than $1000 \mathrm{mg}$. This needs to be clarified in a careful dose-finding study.

A competing company has developed their extract POMELLA based on work at the University of California, Los Angeles. The extract (drug: extract ratio: $50: 1$, solvent not stated) is standardized by HPLC on $30 \%$ of punicalagins in addition to smaller amounts of other marker compounds that exist at concentrations less than $5 \%$ (ellagic acid, gallic acid, and gallagic acid). Batch (Lot number LPR1EP1212L09) contained $300 \mathrm{mg} / 1000 \mathrm{mg}$ punicalagin and $20 \mathrm{mg} /$ ellagic acid/1000 mg (see http://pomextract.com/Pomella-Story_ fc7cfcf6fd873al634.html). A daily dose of $1000 \mathrm{mg}$ of this extract contains at least $320 \mathrm{mg}$ of total polyphenols and is presently being tested in a clinical study [39]. The photometrically assessed polyphenol content varies between 60 and 70\% ([48]; see webpage POMELLA)

For colorimetric quantification of polyphenolic antioxidants in general, the Folin-Ciocalteu assay is used with gallic acid as reference [103]. Theoretically, however, any polyphenol could be used as reference compound (e.g., pyrogallol (Table 1)). Martin et al. [104] proposed replacing gallic acid by a purified pomegranate pomace extract in the Folin-Ciocalteu assay. This purified extract contained at least 5.6\% nonpolyphenols (identified as sugars, moisture, ash, and nitrogen (Kjeldhal assay)) compared with $9.1 \%$ in the raw POMx extract (trademark) [104]. The polyphenolic composition of this purified extract has not been quantified in terms of pure reference compounds. Data are not presented as absolute values but as rough estimates of polyphenol contents expressed as percentages of total polyphenols. When POMx extract was analyzed by Folin-Ciocalteu using the purified extract as reference, the result (unsurprisingly) was $92.6 \%$. This percentage does not necessarily reflect $92.6 \%$ of polyphenols, since the absolute polyphenolic content of the purified pomegranate pomace extract has not been analysed. Thus, though the purified pomegranate pomace extract may well be appropriate for quality control of the POMx extraction process, it does not allow quantification of polyphenols in pomegranate products as suggested by Martin et al. [104]. The $15.7 \%$ of punicalagin expressed as a percentage of the 92.6\% total polyphenols suggests a putative absolute value of $14.5 \%$ of punicalagin in POMx. It remains questionable why POMx has been characterized as extract standardized on $37-40 \%$ punicalagin assessed by HPLC [14]. The FolinCiocalteu assay has never claimed to reflect the absolute polyphenol content of a sample. It has been designed as an index for comparing similar samples [105] by using gallic acid as reference compound. The Folin-Ciocalteu values were not declared on the POMx capsules we bought.

Pomegranate preparations can contain up to 48 phenolic compounds, and the complexity of their polyphenolic profiles necessitates the use of hyphenated techniques for a thorough evaluation of their composition [106-108]. For reasons of expense, only punicalagin, ellagic acid, and anthocyanins are measured in routine laboratories despite the presence of larger concentrations of other ellagitannins in processed pomegranate preparations, as shown by Fischer et al. 2011 $[107,108]$. Although, if all polyphenols in pure pomegranate preparations were included in the HPLC analysis, resulting estimates of total polyphenol content correlated well with photometric estimates, the correlations were very poor if only punicalagin, ellagic acid, and anthocyanins were used. Our results substantiate this (Table 2).

Standardization of products solely on photometric assessments can be misleading and the content of punicalagin, ellagic acid, and anthocyanins as assessed by routine HPLC should be declared on product labels in addition to the photometric estimates. Both indicators should replace descriptions such as the one that came with the extract "Ultra Granatapfel forte," claiming that "the punicalagin dose in one capsule is equivalent to $840 \mathrm{~mL}$ mother juice" (see webpage: Ultra Granatapfel forte Capsules). Such information is unhelpful because one $500 \mathrm{mg}$ capsule contained only $20 \mathrm{mg}$ polyphenols as assessed by HPLC. Depending on what is taken as the benchmark daily dose for prostate cancer-130 or $400 \mathrm{mg}$ ellagitannins-, many capsules of this product may need to be taken daily, which would be inconvenient as well as expensive.

The dose of oral pomegranate fruit extract chosen in mice to inhibit tumorigenesis was based on the assumption that a typical healthy $70 \mathrm{~kg}$ individual may be persuaded to drink $500 \mathrm{~mL}$ of pomegranate juice extracted from two fruits [109], containing a putative polyphenol dose of around $350 \mathrm{mg}$ per day (Table 2). Of the products investigated, this dose is contained in $1000 \mathrm{mg}$ of POMx extract if we can rely on the study by Hong et al. [14] or 3 POMx capsules as currently available (Table 2 ), in $350 \mathrm{~mL}$ (3.5 cups) of pure 
juice L3074, in $12 \mathrm{~mL}$ of the concentrated fermented juice F4 supplemented with elderberry concentrate, in 2-3 of the proprietary capsules GranaProstan, or in 16 of the proprietary capsules Ultra Granatapfel forte (an inappropriate dose). Though these doses are large, they can be used safely in patients [110].

Tables 2 and 3 show that the quantity and the spectrum of phenolic compounds vary greatly in different products, depending partly on the ripeness of the fruits [111]. Fresh pomegranates contained between 11 and $1543 \mathrm{mg}$ anthocyanins/L depending on the colour of the variety, white, rose, dark red, and purple [112]. Fresh juices contained 904 to $2067 \mathrm{mg} / \mathrm{L}$ of total phenols as assessed by FolinCiocalteu [112]. This is in accordance with the study by Gómez-Caravaca and coworkers [113] who found that the total phenolic content ranged from 581 to $2551 \mathrm{mg} / \mathrm{L}$ in the pomegranate juices they investigated. Table 2 shows that only one of our pure juices was within this range. Our anthocyanin: polyphenol ratios were lower than those reported by Gómez-Caravaca and coworkers [113], which varied between 20 to $82 \%$; this may well indicate anthocyanin degradation in the samples we analysed.

Reductions or losses of phenolic compounds have been reported in commercial juices, and these have been attributed to commercial processing procedures [114]. Although mother juices (100\% pure juices) should contain more polyphenols than blended juices, only 3 of 6 pure juices were rich in ellagitannins and antioxidant capacity. Only one of the 6 pure juices that were rich in ellagitannin was also rich in anthocyanins. Some of the other pure juices had even a lower antioxidant capacity than blended juices. In some juices the antioxidant capacity was attributable to vitamin $\mathrm{C}$ rather than to phenolic compounds [106]. Vitamin C may preserve coactive compounds [115].

Factors affecting the stability of anthocyanins in juices include $\mathrm{pH}$, the presence of enzymes and copigments such as metallic ions and sugars and, such processing features as the intensity and duration of heating, the storage temperature, and time and the presence of oxygen and/or light. Shortterm thermal treatments $\left(65\right.$ and $90^{\circ} \mathrm{C}$ for 30 or $5 \mathrm{~s}$ ) decreased the percentage of polymeric anthocyanins and increased the amount of monomeric anthocyanins and thus the bioavailability of coactive compounds [116]. Pasteurization had no influence on the total polyphenols and antioxidant capacity of juices. However, the storage temperature was the main factor affecting all coactive compounds, the total monomeric and individual anthocyanins, the total phenolic compounds, and therefore also the antioxidant activity [116]. Fast degradation of anthocyanins was observed in juices stored at $25^{\circ} \mathrm{C}$, while refrigerated storage at $5^{\circ} \mathrm{C}$ resulted in much slower degradation. Cyanidin-3-O-glucoside was less stable than delphinidin- and cyanidin-3,5-diglucosides. There was a linear relationship between total monomeric anthocyanins and antioxidative capacity [116]. Consistently, liquid pomegranate peel extracts had acceptable thermal stability after sterilization and storage at low temperature [117]. Longer thermal treatment of juices (heating at $90^{\circ} \mathrm{C}$ for $5 \mathrm{~h}$ ) resulted in total anthocyanin losses ranging from $76 \%$ to $87 \%$ of the initial anthocyanin levels. The anthocyanin stability was independent of the total phenolic content and of low and high molecular weight pomegranate matrix components (such as organic acids and sugars) [118]. Exposure to light during storage also affects loss of coactive compound [107, 117]. Good correlation of the anthocyanins with red colour was observed for all samples at elevated temperatures (70$90^{\circ} \mathrm{C}$ ), but the visual appearance did not adequately reflect the quality and storage stability of pomegranate juices [118].

Ellagitannins seem to be the major antioxidants in pomegranate juices [106]. Commercial juices from whole pomegranates contained about $1500-1900 \mathrm{mg} / \mathrm{L}$ punicalagin while only traces of this compound were detected in selfmade freshly squeezed juice from pomegranate arils. The ellagitannins in extracts from whole pomegranate are therefore derived from the peel [119]. Punicalagin concentrations ranged from 1100 to $2000 \mathrm{mg} / \mathrm{kg}$ dry matter of mesocarp and peel and from 4 to $565 \mathrm{mg} / \mathrm{L}$ in aril juices [119]. The punicalagin contents in the two pure juices analysed here are within or above this range (Table 2). For the whole pomegranate fruit extracts the punicalagin content of $95 \%$ relative to the total polyphenols and the low anthocyanin content of around $1 \%$ reflect the extraction from whole pomegranates (Table 2). The anthocyanins in the F4 preparation are derived from the additional elderberry as revealed by the individual elderberry anthocyanin components (Table 3).

Homogenates prepared from the whole fruit showed about a 20-fold higher antioxidant activity than did aril homogenates, which correlated significantly with the content of the four major hydrolyzable tannins (predominantly punicalagin) [120]. Likewise, when extracted with an ethanolacetone extraction solvent, pomegranate peel showed greater antioxidant capacity than did pulp. This was consistent with the higher contents of total phenolics, flavonoids, and proanthocyanidins in the peel extract [121]. No correlation between antioxidant activity and level of anthocyanins was found [120]. When polyphenols purified from peel containing juice products were compared with those from peel-free juice, the radical scavenging effect was lower with the latter [122]. Juicing with peel made the juice bitter and astringent [122].

When 19 pomegranate food supplements were compared, only a limited number of pomegranate supplements were believably authentic. Product labels were inconsistent with polyphenol composition and antioxidant content. Thirteen samples contained disproportionately large amounts of ellagic acid and low or no detectable pomegranate tannins. Only six products had a tannin profile (punicalagin, punicalin, ellagitannins, and gallotannins) consistent with pomegranate. Natural pomegranate extract was the most representative of pomegranate fruit polyphenols with $99 \%$ total pomegranate polyphenol and the highest antioxidant capacity across all measures (Extract 1, lower part of Table 2. There were strong correlations between total polyphenols and antioxidant capacity in products that had polyphenol compositions consistent with a pomegranate source but not with products that contained large amounts of ellagic acid and little or no detectable pomegranate tannins. Thus, regulation of the market is required to assure consumers of the quality of pomegranate supplements $[123,124]$. The content of saccharose and D-sorbit should be negligible, the 
glucose to fructose ratio should be below 1 , the quantity of titratable acid (calculated as citric acid, $\mathrm{pH}$ 8.1) should vary between 1.9 , and $45 \mathrm{~g} / \mathrm{L}$ and malic acid should never be present. A comparative analysis of pomegranate juices and concentrates verified that many commercial products are mixed with sugar, colouring ingredients, and other fruit juices $[112,125]$ : these may or may not influence therapeutic effectiveness.

Processing conditions of the fruits, that is, coextraction of arils and peel and pressure, markedly affected the profiles and contents of phenolics in the pomegranate juices [108], underlining the necessity to optimise these features for obtaining products with well-defined and reproducible functional properties [119]. Heating plus refrigeration may help to reduce anthocyanin degradation in pasteurized pomegranate juice, avoiding a dramatic impact on its colour and preserving the beneficial effects [116]. Future research should identify the optimum coactive compound composition of a pomegranate preparation for the treatment of prostate cancer [120] with the primary outcome of 5-year survival. Declaration of the content of coactive constituents helps to identify quality products. However, direct evidence for bioequivalence between products can only come from wellplanned clinical studies. Because of the complexity of the coactive pomegranate compounds, similar bioavailabilities of coactive compounds cannot provide indirect evidence for bioequivalence unless the clinical effectiveness for the leading polyphenol mixture has been confidently established [126]. This is because bioequivalence requires not only pharmaceutical similarity of components, but also their pharmacological and therapeutic equivalence.

Ellagic acid and its metabolites are found in human plasma after ingestion of pomegranate. Its antioxidant capacity was retained ex vivo [127]. An average ellagic acid serum concentration of $0.14 \mu \mathrm{M} / \mathrm{L}$ was attained after consumption of a proprietary pomegranate extract and was associated with a putative anticancer effect [36]. Although similar ellagic acid serum concentrations were attained after taking extract or juice [23], another study showed lower concentrations of $0.06 \mu \mathrm{M} / \mathrm{L}$ after drinking $180 \mathrm{~mL}$ of a pomegranate juice [128]. As long as we do not know which polyphenol (or polyphenols) is (or are) responsible for the putative anticancer effect, it is unwise to base dosing of pomegranate products on ellagic acid, because serum ellagic acid or its metabolites are the metabolites of various oligomeric polyphenols. Pharmacodynamic or ex vivo/in vitro tests are not surrogates for bioequivalence unless the results can be shown to correlate with therapeutic effectiveness [126].

In summary, there is evidence that pomegranate has a putative anticancerogenic effect in prostate cancer and can safely be used in high doses. But commercial pomegranate products vary greatly in their content of coactive ingredients. For reasons of transparency, consumers should know not only the photometric quantification of the polyphenols in the daily recommended dosage, but also the content of HPLCanalysed polyphenols. Only then can they choose a dose that has a chance of being effective in the treatment of cancer. The preparation of pomegranate end-products is affected by many determinants. Their declaration should be incorporated into the regulatory guidance and controlled before pomegranate products are allowed on the market.

\section{Conflict of Interests}

The authors declare that there is no conflict of interests regarding the publication of this paper.

\section{References}

[1] V. M. Adhami, N. Khan, and H. Mukhtar, "Cancer chemoprevention by pomegranate: laboratory and clinical evidence," Nutrition and Cancer, vol. 61, no. 6, pp. 811-815, 2009.

[2] M. Toi, H. Bando, C. Ramachandran et al., "Preliminary studies on the anti-angiogenic potential of pomegranate fractions in vitro and in vivo," Angiogenesis, vol. 6, no. 2, pp. 121-128, 2003.

[3] S. Koyama, L. J. Cobb, H. H. Mehta et al., "Pomegranate extract induces apoptosis in human prostate cancer cells by modulation of the IGF-IGFBP axis," Growth Hormone and IGF Research, vol. 20, no. 1, pp. 55-62, 2010.

[4] M. B. Rettig, D. Heber, J. An et al., "Pomegranate extract inhibits androgen-independent prostate cancer growth through a nuclear factor- $\kappa \mathrm{B}$-dependent mechanism," Molecular Cancer Therapeutics, vol. 7, no. 9, pp. 2662-2671, 2008.

[5] A. Malik, F. Afaq, S. Sarfaraz, V. M. Adhami, D. N. Syed, and H. Mukhtar, "Pomegranate fruit juice for chemoprevention and chemotherapy of prostate cancer," Proceedings of the National Academy of Sciences of the United States of America, vol. 102, no. 41, pp. 14813-14818, 2005.

[6] A. Bishayee, R. J. Thoppil, A. S. Darvesh, V. Ohanyan, J. G. Meszaros, and D. Bhatia, "Pomegranate phytoconstituents blunt the inflammatory cascade in a chemically induced rodent model of hepatocellular carcinogenesis," Journal of Nutritional Biochemistry, vol. 24, no. 1, pp. 178-187, 2013.

[7] P. Filannino, L. Azzi, I. Cavoski et al., "Exploitation of the health-promoting and sensory properties of organic pomegranate (Punica granatum L.) juice through lactic acid fermentation," International Journal of Food Microbiology, vol. 163, no. 2-3, pp. 184-192, 2013.

[8] N. D. Kim, R. Mehta, W. Yu et al., "Chemopreventive and adjuvant therapeutic potential of pomegranate (Punica granatum) for human breast cancer," Breast Cancer Research and Treatment, vol. 71, no. 3, pp. 203-217, 2002.

[9] R. Mehta and E. P. Lansky, "Breast cancer chemopreventive properties of pomegranate (Punica granatum) fruit extracts in a mouse mammary organ culture," European Journal of Cancer Prevention, vol. 13, no. 4, pp. 345-348, 2004.

[10] F. Aqil, R. Munagala, M. V. Vadhanam et al., "Anti-proliferative activity and protection against oxidative DNA damage by punicalagin isolated from pomegranate husk," Food Research International, vol. 49, no. 1, pp. 345-353, 2012.

[11] M. Larrosa, F. A. Tomás-Barberán, and J. C. Espín, "The dietary hydrolysable tannin punicalagin releases ellagic acid that induces apoptosis in human colon adenocarcinoma Caco-2 cells by using the mitochondrial pathway," Journal of Nutritional Biochemistry, vol. 17, no. 9, pp. 611-625, 2006.

[12] C. Palmieri, D. K. Patten, A. Januszewski, G. Zucchini, and S. J. Howell, "Breast cancer: current and future endocrine therapies," Molecular and Cellular Endocrinology, vol. 382, no. 1, pp. 695723, 2014. 
[13] S. Banerjee, S. Kambhampati, I. Haque, and S. K. Banerjee, "Pomegranate sensitizes Tamoxifen action in ER- $\alpha$ positive breast cancer cells," Journal of Cell Communication and Signaling, vol. 5, no. 4, pp. 317-324, 2011.

[14] M. Y. Hong, N. P. Seeram, and D. Heber, "Pomegranate polyphenols down-regulate expression of androgen-synthesizing genes in human prostate cancer cells overexpressing the androgen receptor," Journal of Nutritional Biochemistry, vol. 19, no. 12, pp. 848-855, 2008.

[15] P. Pitchakarn, T. Chewonarin, K. Ogawa et al., "Ellagic acid inhibits migration and invasion by prostate cancer cell lines," Asian Pacific Journal of Cancer Prevention, vol. 14, no. 5, pp. 2859-2863, 2013.

[16] M. Albrecht, W. Jiang, J. Kumi-Diaka et al., "Pomegranate extracts potently suppress proliferation, xenograft growth, and invasion of human prostate cancer cells," Journal of Medicinal Food, vol. 7, no. 3, pp. 274-283, 2004.

[17] N. P. Seeram, L. S. Adams, S. M. Henning et al., "In vitro antiproliferative, apoptotic and antioxidant activities of punicalagin, ellagic acid and a total pomegranate tannin extract are enhanced in combination with other polyphenols as found in pomegranate juice," Journal of Nutritional Biochemistry, vol. 16, no. 6, pp. 360-367, 2005.

[18] M. R. Sartippour, N. P. Seeram, J. Y. Rao et al., "Ellagitannin-rich pomegranate extract inhibits angiogenesis in prostate cancer in vitro and in vivo," International Journal of Oncology, vol. 32, no. 2, pp. 475-480, 2008.

[19] A. Malik and H. Mukhtar, "Prostate cancer prevention through pomegranate fruit," Cell Cycle, vol. 5, no. 4, pp. 371-373, 2006.

[20] N. P. Seeram, W. J. Aronson, Y. Zhang et al., "Pomegranate ellagitannin-derived metabolites inhibit prostate cancer growth and localize to the mouse prostate gland," Journal of Agricultural and Food Chemistry, vol. 55, no. 19, pp. 7732-7737, 2007.

[21] L. S. Adams, Y. Zhang, N. P. Seeram, D. Heber, and S. Chen, "Pomegranate ellagitannin-derived compounds exhibit antiproferative and antiaromatase activity in breast cancer cells in vitro," Cancer Prevention Research, vol. 3, no. 1, pp. 108-113, 2010.

[22] R. Vicinanza, Y. Zhang, S. M. Henning, and D. Heber, "Pomegranate juice metabolites, ellagic acid and urolithin a, synergistically inhibit androgen-independent prostate cancer cell growth via distinct effects on cell cycle control and apoptosis," Evidence-based Complementary and Alternative Medicine, vol. 2013, Article ID 247504, 12 pages, 2013.

[23] N. P. Seeram, Y. Zhang, R. McKeever et al., "Pomegranate juice and extracts provide similar levels of plasma and urinary ellagitannin metabolites in human subjects," Journal of Medicinal Food, vol. 11, no. 2, pp. 390-394, 2008.

[24] B. Cerdá, J. C. Espín, S. Parra, P. Martínez, and F. A. TomásBarberán, "The potent in vitro antioxidant ellagitannins from pomegranate juice are metabolised into bioavailable but poor antioxidant hydroxy-6H-dibenzopyran-6-one derivatives by the colonic microflora of healthy humans," European Journal of Nutrition, vol. 43, no. 4, pp. 205-220, 2004.

[25] R. Agosti, R. K. Duke, J. E. Chrubasik, and S. Chrubasik, "Effectiveness of Petasites hybridus preparations in the prophylaxis of migraine: a systematic review," Phytomedicine, vol. 13, no. 9-10, pp. 743-746, 2006.

[26] S. Chrubasik, C. Conradt, and B. D. Roufogalis, "Effectiveness of Harpagophytum extracts and clinical efficacy," Phytotherapy Research, vol. 18, no. 2, pp. 187-189, 2004.
[27] J. J. Gagnier, S. Chrubasik, and E. Manheimer, "Harpgophytum procumbens for osteoarthritis and low back pain: a systematic review," BMC Complementary and Alternative Medicine, vol. 4, article 13, 2004.

[28] C. Chrubasik, R. K. Duke, and S. Chrubasik, "The evidence for clinical efficacy of rose hip and seed: a systematic review," Phytotherapy Research, vol. 20, no. 1, pp. 1-3, 2006.

[29] J. E. Chrubasik, B. D. Roufogalis, H. Wagner, and S. A. Chrubasik, "A comprehensive review on nettle effect and efficacy profiles, part I: herba urticae," Phytomedicine, vol. 14, no. 6, pp. 423-435, 2007.

[30] J. E. Chrubasik, B. D. Roufogalis, H. Wagner, and S. Chrubasik, "A comprehensive review on the stinging nettle effect and efficacy profiles. Part II: urticae radix," Phytomedicine, vol. 14, no. 7-8, pp. 568-579, 2007.

[31] C. Chrubasik, B. D. Roufogalis, U. Müller-Ladner, and S. Chrubasik, "A systematic review on the Rosa canina effect and efficacy profiles," Phytotherapy Research, vol. 22, no. 6, pp. 725733, 2008.

[32] C. Chrubasik, G. Li, and S. Chrubasik, "The clinical effectiveness of chokeberry: a systematic review," Phytotherapy Research, vol. 24, no. 8, pp. 1107-1114, 2010.

[33] J. E. Vlachojannis, M. Cameron, and S. Chrubasik, "A systematic review on the effectiveness of willow bark for musculoskeletal pain," Phytotherapy Research, vol. 23, no. 7, pp. 897-900, 2009.

[34] J. E. Vlachojannis, M. Cameron, and S. Chrubasik, "A systematic review on the Sambuci fructus effect and efficacy profiles," Phytotherapy Research, vol. 24, no. 1, pp. 1-8, 2010.

[35] J. E. Vlachojannis, M. Cameron, and S. Chrubasik, "Medicinal use of potato-derived products: a systematic review," Phytotherapy Research, vol. 24, no. 2, pp. 159-162, 2010.

[36] A. J. Pantuck, J. T. Leppert, N. Zomorodian et al., "Phase II study of pomegranate juice for men with rising prostate-specific antigen following surgery or radiation for prostate cancer," Clinical Cancer Research, vol. 12, no. 13, pp. 4018-4026, 2006.

[37] C. J. Paller, X. Ye, P. J. Wozniak et al., "A randomized phase II study of pomegranate extract for men with rising PSA following initial therapy for localized prostate cancer," Prostate Cancer and Prostatic Diseases, vol. 16, no. 1, pp. 50-55, 2013.

[38] S. J. Freedland, M. Carducci, N. Kroeger et al., "A double-blind, randomized, neoadjuvant study of the tissue effects of POMx pills in men with prostate cancer before radical prostatectomy," Cancer Prevention Research, vol. 6, no. 10, pp. 1120-1127, 2013.

[39] N. Kroeger, A. S. Belldegrun, and A. J. Pantuck, "Pomegranate extracts in the management of men's urologic health: Scientific rationale and preclinical and clinical data," Evidence-Based Complementary and Alternative Medicine, vol. 2013, Article ID 701434, 9 pages, 2013.

[40] F. Stenner-Liewen, H. Liewen, R. Cathomas et al., "Daily pomegranate intake has no impact on PSA levels in patients with advanced prostate cancer-results of a phase IIb randomized controlled trial," Journal of Cancer, vol. 4, no. 7, pp. 597-605, 2013.

[41] S. Chrubasik-Hausmann, C. Vlachojannis, and B. Zimmermann, "Pomegranate juice and prostate cancer: importance of the characterisation of the active principle," Phytotherapy Research, 2014.

[42] E. Davidson, J. Vlachojannis, M. Cameron, and S. Chrubasik, "Best available evidence in cochrane reviews on herbal medicine?" Evidence-Based Complementary and Alternative Medicine, vol. 2013, Article ID 163412, 7 pages, 2013. 
[43] S. Chrubasik-Hausmann, C. Vlachojannis, and B. F. Zimmermann, "Proanthocyanin content in cranberry CE medicinal products," Phytotherapy Research, 2014.

[44] E. Davidson, B. F. Zimmermann, E. Jungfer, and S. ChrubasikHausmann, "Prevention of urinary tract infections with Vaccinium products," Phytotherapy Research, vol. 28, no. 3, pp. 465470, 2014.

[45] D. S. Ming, S. Pham, S. Deb et al., "Pomegranate extracts impact the androgen biosynthesis pathways in prostate cancer models in vitro and in vivo," The Journal of Steroid Biochemistry and Molecular Biology, vol. 143, pp. 19-28, 2014.

[46] Y. Wang, S. Zhang, S. Iqbal et al., "Pomegranate extract inhibits the bone metastatic growth of human prostate cancer cells and enhances the in vivo efficacy of docetaxel chemotherapy," Prostate, vol. 74, no. 5, pp. 497-508, 2014.

[47] B. Cerdá, J. J. Cerón, F. A. Tomás-Barberán, and J. C. Espín, "Repeated oral administration of high doses of the pomegranate ellagitannin punicalagin to rats for 37 days is not toxic," Journal of Agricultural and Food Chemistry, vol. 51, no. 11, pp. 3493-3501, 2003.

[48] C. Patel, P. Dadhaniya, L. Hingorani, and M. G. Soni, "Safety assessment of pomegranate fruit extract: acute and subchronic toxicity studies," Food and Chemical Toxicology, vol. 46, no. 8, pp. 2728-2735, 2008.

[49] R. K. Kishore, D. Sudhakar, and P. R. Parthasarathy, "Embryo protective effect of pomegranate (Punica granatum L.) fruit extract in adriamycin-induced oxidative stress," Indian Journal of Biochemistry and Biophysics, vol. 46, no. 1, pp. 106-111, 2009.

[50] K. P. Leiva, J. Rubio, F. Peralta, and G. F. Gonzales, "Effect of Punica granatum (pomegranate) on sperm production in male rats treated with lead acetate," Toxicology Mechanisms and Methods, vol. 21, no. 6, pp. 495-502, 2011.

[51] C. Fimognari, P. Sestili, M. Lenzi, A. Bucchini, G. Cantelli-Forti, and P. Hrelia, "RNA as a new target for toxic and protective agents," Mutation Research-Fundamental and Molecular Mechanisms of Mutagenesis, vol. 648, no. 1-2, pp. 15-22, 2008.

[52] E. M. Al-Olayan, M. F. El-Khadragy, D. M. Metwally, and A. E. Abdel Moneim, "Protective effects of pomegranate ( Punica granatum) juice on testes against carbon tetrachloride intoxication in rats," BMC Complementary and Alternative Medicine, vol. 14, article 164, 2014.

[53] V. Şen, M. Bozkurt, S. Söker et al., “The effects of pomegranate and carvacrol on methotrexate-induced bone marrow toxicity in rats," Clinical and Investigative Medicine, vol. 37, no. 2, pp. E93-E101, 2014.

[54] F. Çelik, C. Gocmez, M. Bozkurt et al., "Neuroprotective effects of carvacrol and pomegranate against methotrexateinduced toxicity in rats," European Review for Medical and Pharmacological Sciences, vol. 17, no. 22, pp. 2988-2993, 2013.

[55] A. E. Abdel Moneim, M. S. Othman, S. M. Mohmoud, and K. M. El-Deib, "Pomegranate peel attenuates aluminum-induced hepatorenal toxicity," Toxicology Mechanisms and Methods, vol. 23, no. 8, pp. 624-633, 2013.

[56] D. Kumar, S. Singh, A. K. Singh, and S. I. Rizvi, "Pomegranate (Punica granatum) peel extract provides protection against mercuric chloride-induced oxidative stress in Wistar strain rats," Pharmaceutical Biology, vol. 51, no. 4, pp. 441-446, 2013.

[57] M. Cekmen, A. Otunctemur, E. Ozbek et al., "Pomegranate extract attenuates gentamicin-induced nephrotoxicity in rats by reducing oxidative stress," Renal Failure, vol. 35, no. 2, pp. 268274,2013
[58] M. T. Boroushaki, D. Arshadi, H. Jalili-Rasti, E. Asadpour, and A. Hosseini, "Protective effect of pomegranate seed oil against acute toxicity of diazinon in rat kidney," Iranian Journal of Pharmaceutical Research, vol. 12, no. 4, pp. 821-827, 2013.

[59] M. T. Bouroshaki, H. R. Sadeghnia, M. Banihasan, and S. Yavari, "Protective effect of pomegranate seed oil on hexachlorobutadiene-induced nephrotoxicity in rat kidneys," Renal Failure, vol. 32, no. 5, pp. 612-617, 2010.

[60] I. A. T. M. Meerts, C. M. Verspeek-Rip, C. A. F. Buskens et al., "Toxicological evaluation of pomegranate seed oil," Food and Chemical Toxicology, vol. 47, no. 6, pp. 1085-1092, 2009.

[61] A. Faria, R. Monteiro, N. Mateus, I. Azevedo, and C. Calhau, "Effect of pomegranate (Punica granatum) juice intake on hepatic oxidative stress," European Journal of Nutrition, vol. 46, no. 5, pp. 271-278, 2007.

[62] M. Pirinççioğlu, G. Kizil, M. Kizil, G. Özdemir, Z. Kanay, and M. A. Ketani, "Protective effect of Öküzgözü (Vitis vinifera L. cv.) grape juice against carbon tetrachloride induced oxidative stress in rats," Food and Function, vol. 3, no. 6, pp. 668-673, 2012.

[63] A. E. Abdel Moneim and M. F. El-Khadragy, "The potential effects of pomegranate (Punica granatum) juice on carbon tetrachloride-induced nephrotoxicity in rats," Journal of Physiology and Biochemistry, vol. 69, no. 3, pp. 359-370, 2013.

[64] V. Tugcu, E. Kemahli, E. Ozbek et al., "Protective effect of a potent antioxidant, pomegranate juice, in the kidney of rats with nephrolithiasis induced by ethylene glycol," Journal of Endourology, vol. 22, no. 12, pp. 2723-2731, 2008.

[65] J. Boateng, M. Verghese, L. Shackelford et al., "Selected fruits reduce azoxymethane (AOM)-induced aberrant crypt foci (ACF) in Fisher 344 male rats," Food and Chemical Toxicology, vol. 45, no. 5, pp. 725-732, 2007.

[66] Z. M. Yazici, A. Meric, A. Midi, Y. V. ArInc, V. Kahya, and G. Haflz, "Reduction of cisplatin ototoxicity in rats by oral administration of pomegranate extract," European Archives of Oto-Rhino-Laryngology, vol. 269, no. 1, pp. 45-52, 2012.

[67] V. Kahya, B. Ozucer, R. Dogan et al., "Pomegranate extract: a potential protector against aminoglycoside ototoxicity," Journal of Laryngology and Otology, vol. 128, no. 1, pp. 43-48, 2014.

[68] M. Hassanpour Fard, A. E. Ghule, S. L. Bodhankar, and M. Dikshit, "Cardioprotective effect of whole fruit extract of pomegranate on doxorubicin-induced toxicity in rat," Pharmaceutical Biology, vol. 49, no. 4, pp. 377-382, 2011.

[69] A. Vidal, A. Fallarero, B. R. Peña et al., "Studies on the toxicity of Punica granatum L. (Punicaceae) whole fruit extracts," Journal of Ethnopharmacology, vol. 89, no. 2-3, pp. 295-300, 2003.

[70] P. S. Negi, G. K. Jayaprakasha, and B. S. Jena, "Antioxidant and antimutagenic activities of pomegranate peel extracts," Food Chemistry, vol. 80, no. 3, pp. 393-397, 2003.

[71] M. Zahin, F. Aqil, and I. Ahmad, "Broad spectrum antimutagenic activity of antioxidant active fraction of Punica granatum L. peel extracts," Mutation Research-Genetic Toxicology and Environmental Mutagenesis, vol. 703, no. 2, pp. 99-107, 2010.

[72] A. de Amorim, H. R. Borba, and J. L. Armada, "Test of mutagenesis in mice treated with aqueous extracts from Punica granatum L. (Pomegranate)," Revista Brasileira de Farmacia, vol. 76, no. 4, pp. 110-111, 1995.

[73] M. C. Valadares, E. R. T. Pereira, P. L. Benfica, and J. R. Paula, "Assessment of mutagenic and antimutagenic effects of Punica granatum in mice," Brazilian Journal of Pharmaceutical Sciences, vol. 46, no. 1, pp. 121-127, 2010. 
[74] A. Sánchez-Lamar, G. Fonseca, J. L. Fuentes et al., "Assessment of the genotoxic risk of Punica granatum L. (Punicaceae) whole fruit extracts," Journal of Ethnopharmacology, vol. 115, no. 3, pp. 416-422, 2008.

[75] S. M. Tripathi and D. K. Singh, "Molluscicidal activity of Punica granatum bark and Canna indica root," Brazilian Journal of Medical and Biological Research, vol. 33, no. 11, pp. 1351-1355, 2000.

[76] L. Ferrara, O. Schettino, P. Forgione, V. Rullo, and S. Di Gennaro, "Identification of the root of Punica granatum in galenic preparations using TLC," Bollettino della Societa Italiana di Biologia Sperimentale, vol. 65, no. 5, pp. 385-390, 1989.

[77] E. P. Lansky and R. A. Newman, "Punica granatum (pomegranate) and its potential for prevention and treatment of inflammation and cancer," Journal of Ethnopharmacology, vol. 109, no. 2, pp. 177-206, 2007.

[78] S. Okonogi, C. Duangrat, S. Anuchpreeda, S. Tachakittirungrod, and S. Chowwanapoonpohn, "Comparison of antioxidant capacities and cytotoxicities of certain fruit peels," Food Chemistry, vol. 103, no. 3, pp. 839-846, 2007.

[79] D. Heber, N. P. Seeram, H. Wyatt et al., "Safety and antioxidant activity of a pomegranate ellagitannin-enriched polyphenol dietary supplement in overweight individuals with increased waist size," Journal of Agricultural and Food Chemistry, vol. 55, no. 24, pp. 10050-10054, 2007.

[80] M. Rosenblat, T. Hayek, and M. Aviram, "Anti-oxidative effects of pomegranate juice (PJ) consumption by diabetic patients on serum and on macrophages," Atherosclerosis, vol. 187, no. 2, pp. 363-371, 2006.

[81] M. Aviram and L. Dornfeld, "Pomegranate juice consumption inhibits serum angiotensin converting enzyme activity and reduces systolic blood pressure," Atherosclerosis, vol. 158, no. 1, pp. 195-198, 2001.

[82] M. D. Sumner, M. Elliott-Eller, G. Weidner et al., "Effects of pomegranate juice consumption on myocardial perfusion in patients with coronary heart disease," The American Journal of Cardiology, vol. 96, no. 6, pp. 810-814, 2005.

[83] B. Cerdá, C. Soto, M. D. Albaladejo et al., "Pomegranate juice supplementation in chronic obstructive pulmonary disease: a 5-week randomized, double-blind, placebo-controlled trial," European Journal of Clinical Nutrition, vol. 60, no. 2, pp. 245253, 2006.

[84] C. P. Forest, H. Padma-Nathan, and H. R. Liker, "Efficacy and safety of pomegranate juice on improvement of erectile dysfunction in male patients with mild to moderate erectile dysfunction: a randomized, placebo-controlled, double-blind, crossover study," International Journal of Impotence Research, vol. 19, no. 6, pp. 564-567, 2007.

[85] A. Basu, E. D. Newman, A. L. Bryant, T. J. Lyons, and N. M. Betts, "Pomegranate polyphenols lower lipid peroxidation in adults with type 2 diabetes but have no effects in healthy volunteers: a pilot study," Journal of Nutrition and Metabolism, vol. 2013, Article ID 708381, 7 pages, 2013.

[86] M. Aviram, M. Rosenblat, D. Gaitini et al., "Pomegranate juice consumption for 3 years by patients with carotid artery stenosis reduces common carotid intima-media thickness, blood pressure and LDL oxidation," Clinical Nutrition, vol. 27, no. 4, p. 671, 2008.

[87] T. Ismail, P. Sestili, and S. Akhtar, "Pomegranate peel and fruit extracts: a review of potential anti-inflammatory and antiinfective effects," Journal of Ethnopharmacology, vol. 143, no. 2, pp. 397-405, 2012.
[88] T. Yamamoto, K. Asakura, H. Shirasaki, and T. Himi, "Questionnaire about the intake of and hypersensitivity to fruits, vegetables and nuts including birch pollen related foods," Journal of Otolaryngology of Japan, vol. 116, no. 7, pp. 779-788, 2013.

[89] B. Buyuktiryaki, B. Bartolomé, U. M. Sahiner et al., "Pomegranate allergy and pathogenesis-related protein 4," Annals of Allergy, Asthma and Immunology, vol. 111, no. 3, pp. 231-232, 2013.

[90] E. Damiani, A. M. Aloia, M. G. Priore, S. Nardulli, and A. Ferrannini, "Pomegranate (Punica granatum) allergy: clinical and immunological findings," Annals of Allergy, Asthma and Immunology, vol. 103, no. 2, pp. 178-180, 2009.

[91] P. Gaig, B. Bartolomé, R. Lleonart, P. García-Ortega, R. Palacios, and C. Richart, "Allergy to pomegranate (Punica granatum)," Allergy, vol. 54, no. 3, pp. 287-288, 1999.

[92] J. M. Igea, J. Cuesta, M. Cuevas et al., "Adverse reaction to pomegranate ingestion," Allergy, vol. 46, no. 6, pp. 472-474, 1991.

[93] S. Gangemi, G. Mistrello, D. Roncarolo, S. Amato, and P. L. Minciullo, "Pomegranate-dependent exercise-induced anaphylaxis," Journal of Investigational Allergology and Clinical Immunology, vol. 18, no. 6, pp. 491-492, 2008.

[94] V. L. Hegde and Y. P. Venkatesh, "Anaphylaxis to excipient mannitol: evidence for an immunoglobulin E-mediated mechanism," Clinical and Experimental Allergy, vol. 34, no. 10, pp. 1602-1609, 2004.

[95] M. Nagata, M. Hidaka, H. Sekiya et al., "Effects of pomegranate juice on human cytochrome P450 2C9 and tolbutamide pharmacokinetics in rats," Drug Metabolism and Disposition, vol. 35, no. 2, pp. 302-305, 2007.

[96] M. Hidaka, M. Okumura, K.-I. Fujita et al., "Effects of pomegranate juice on human cytochrome P450 3A (CYP3A) and carbamazepine pharmacokinetics in rats," Drug Metabolism and Disposition, vol. 33, no. 5, pp. 644-648, 2005.

[97] H. Kim, Y. J. Yoon, J. H. Shon, I. J. Cha, J. G. Shin, and K. H. Liu, "Inhibitory effects of fruit juices on CYP3A activity," Drug Metabolism and Disposition, vol. 34, no. 4, pp. 521-523, 2006.

[98] D. Farkas, L. E. Oleson, Y. Zhao et al., "Pomegranate juice does not impair clearance of oral or intravenous midazolam, a probe for cytochrome P450-3A activity: comparison with grapefruit juice," Journal of Clinical Pharmacology, vol. 47, no. 3, pp. 286294, 2007.

[99] A. V. Sorokin, B. Duncan, R. Panetta, and P. D. Thompson, "Rhabdomyolysis associated with pomegranate juice consumption," The American Journal of Cardiology, vol. 98, no. 5, pp. 705706, 2006.

[100] T. Khuu, A. Hickey, and M. C. Deng, "Pomegranate-containing products and tacrolimus: a potential interaction," Journal of Heart and Lung Transplantation, vol. 32, no. 2, pp. 272-274, 2013.

[101] D. Farkas and D. J. Greenblatt, "Influence of fruit juices on drug disposition: discrepancies between in vitro and clinical studies," Expert Opinion on Drug Metabolism and Toxicology, vol. 4, no. 4, pp. 381-393, 2008.

[102] A. McCutcheon, J. Udani, and D. J. Brown, Therapeutic Monograph and Clinical Overview of POM Wonderful Pomegranate Juice, American Botanical Council, 2008.

[103] E. A. Ainsworth and K. M. Gillespie, "Estimation of total phenolic content and other oxidation substrates in plant tissues using Folin-Ciocalteu reagent," Nature Protocols, vol. 2, no. 4, pp. $875-877,2007$. 
[104] K. R. Martin, C. G. Krueger, G. Rodriquez, M. Dreher, and J. D. Reed, "Development of a novel pomegranate standard and new method for the quantitative measurement of pomegranate polyphenols," Journal of the Science of Food and Agriculture, vol. 89, no. 1, pp. 157-162, 2009.

[105] V. L. Singleton, R. Orthofer, and R. M. Lamuela-Raventós, "Analysis of total phenols and other oxidation substrates and antioxidants by means of folin-ciocalteu reagent," Methods in Enzymology, vol. 299, pp. 152-178, 1998.

[106] G. Borges, W. Mullen, and A. Crozier, "Comparison of the polyphenolic composition and antioxidant activity of European commercial fruit juices," Food and Function, vol. 1, no. 1, pp. 7383, 2010.

[107] U. A. Fischer, R. Carle, and D. R. Kammerer, "Identification and quantification of phenolic compounds from pomegranate (Punica granatum L.) peel, mesocarp, aril and differently produced juices by HPLC-DAD-ESI/MSn," Food Chemistry, vol. 127, no. 2, pp. 807-821, 2011.

[108] U. A. Fischer, J. S. Dettmann, R. Carle, and D. R. Kammerer, "Impact of processing and storage on the phenolic profiles and contents of pomegranate (Punica granatum L.) juices," European Food Research and Technology, vol. 233, no. 5, pp. 797-816, 2011.

[109] N. Khan, F. Afaq, M. H. Kweon, K. Kim, and H. Mukhtar, "Oral consumption of pomegranate fruit extract inhibits growth and progression of primary lung tumors in mice," Cancer Research, vol. 67, no. 7, pp. 3475-3482, 2007.

[110] M. Viladomiu, R. Hontecillas, P. Lu, and J. BassaganyaRiera, "Preventive and prophylactic mechanisms of action of pomegranate bioactive constituents," Evidence-Based Complementary and Alternative Medicine, vol. 2013, Article ID 789764 , 18 pages, 2013.

[111] A. Galindo, Á. Calín-Sánchez, J. Collado-González et al., "Phytochemical and quality attributes of pomegranate fruits for juice consumption as affected by ripening stage and deficit irrigation," Journal of the Science of Food and Agriculture, vol. 94, no. 11, pp. 2259-2265, 2014.

[112] M. Fischer-Zorn and V. Ara, "Granatapfelsaft-Chemische Zusammensetzung und mögliche Verfälschungen," Flüssiges Obst, vol. 8, pp. 386-393, 2007.

[113] A. M. Gómez-Caravaca, V. Verardo, M. Toselli, A. SeguraCarretero, A. Fernández-Gutiérrez, and M. F. Caboni, "Determination of the major phenolic compounds in pomegranate juices by HPLC-DAD-ESI-MS," Journal of Agricultural and Food Chemistry, vol. 61, no. 22, pp. 5328-5337, 2013.

[114] G. A. Spanos, R. E. Wrolstad, and D. A. Heatherbell, "Influence of processing and storage on the phenolic composition of apple juice," Journal of Agricultural and Food Chemistry, vol. 38, no. 7, pp. 1572-1579, 1990.

[115] B. W. Bolling, Y.-Y. Chen, and C.-Y. O. Chen, "Contributions of phenolics and added vitamin $\mathrm{C}$ to the antioxidant capacity of pomegranate and grape juices: synergism and antagonism among constituents," International Journal of Food Science and Technology, vol. 48, no. 12, pp. 2650-2658, 2013.

[116] S. Vegara, P. Mena, N. Martí, D. Saura, and M. Valero, "Approaches to understanding the contribution of anthocyanins to the antioxidant capacity of pasteurized pomegranate juices," Food Chemistry, vol. 141, no. 3, pp. 1630-1636, 2013.

[117] W. Qu, P. Li, J. Hong et al., "Thermal stability of liquid antioxidative extracts from pomegranate peel," Journal of the Science of Food and Agriculture, vol. 94, no. 5, pp. 1005-1012, 2013.
[118] U. A. Fischer, R. Carle, and D. R. Kammerer, "Thermal stability of anthocyanins and colourless phenolics in pomegranate (Punica granatum L.) juices and model solutions," Food Chemistry, vol. 138, no. 2-3, pp. 1800-1809, 2013.

[119] M. I. Gil, F. A. Tomas-Barberan, B. Hess-Pierce, D. M. Holcroft, and A. A. Kader, "Antioxidant activity of pomegranate juice and its relationship with phenolic composition and processing," Journal of Agricultural and Food Chemistry, vol. 48, no. 10, pp. 4581-4589, 2000.

[120] R. Tzulker, I. Glazer, I. Bar-Ilan, D. Holland, M. Aviram, and R. Amir, "Antioxidant activity, polyphenol content, and related compounds in different fruit juices and homogenates prepared from 29 different pomegranate accessions," Journal of Agricultural and Food Chemistry, vol. 55, no. 23, pp. 9559-9570, 2007.

[121] Y. Li, C. Guo, J. Yang, J. Wei, J. Xu, and S. Cheng, "Evaluation of antioxidant properties of pomegranate peel extract in comparison with pomegranate pulp extract," Food Chemistry, vol. 96, no. 2, pp. 254-260, 2006.

[122] H. Wasila, X. Li, L. Liu, I. Ahmad, and S. Ahmad, "Peel effects on phenolic composition, antioxidant activity, and making of pomegranate juice and wine," Journal of Food Science, vol. 78, no. 8, pp. C1166-C1172, 2013.

[123] S. Madrigal-Carballo, G. Rodriguez, C. G. Krueger, M. Dreher, and J. D. Reed, "Pomegranate (Punica granatum) supplements: authenticity, antioxidant and polyphenol composition," Journal of Functional Foods, vol. 1, no. 3, pp. 324-329, 2009.

[124] G. Borges and A. Crozier, "HPLC-PDA-MS fingerprinting to assess the authenticity of pomegranate beverages," Food Chemistry, vol. 135, no. 3, pp. 1863-1867, 2012.

[125] F. Tezcan, S. Uzaşçi, G. Uyar, N. Öztekin, and F. Bedia Erim, "Determination of amino acids in pomegranate juices and fingerprint for adulteration with apple juices," Food Chemistry, vol. 141, no. 2, pp. 1187-1191, 2013.

[126] S. Chrubasik and B. Roufogalis, "Bioequivalence of herbal medicines," The New Zealand Journal of Pharmaceutical, vol. 53, pp. 39-44, 2003.

[127] S. U. Mertens-Talcott, P. Jilma-Stohlawetz, J. Rios, L. Hingorani, and H. Derendorf, "Absorption, metabolism, and antioxidant effects of pomegranate (Punica granatum L.) polyphenols after ingestion of a standardized extract in healthy human volunteers," Journal of Agricultural and Food Chemistry, vol. 54, no. 23, pp. 8956-8961, 2006.

[128] N. P. Seeram, S. M. Henning, Y. Zhang, M. Suchard, Z. Li, and D. Heber, "Pomegranate juice ellagitannin metabolites are present in human plasma and some persist in urine for up to 48 hours," Journal of Nutrition, vol. 136, no. 10, pp. 2481-2485, 2006. 


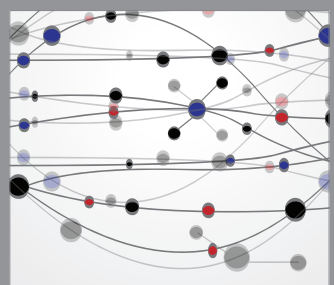

The Scientific World Journal
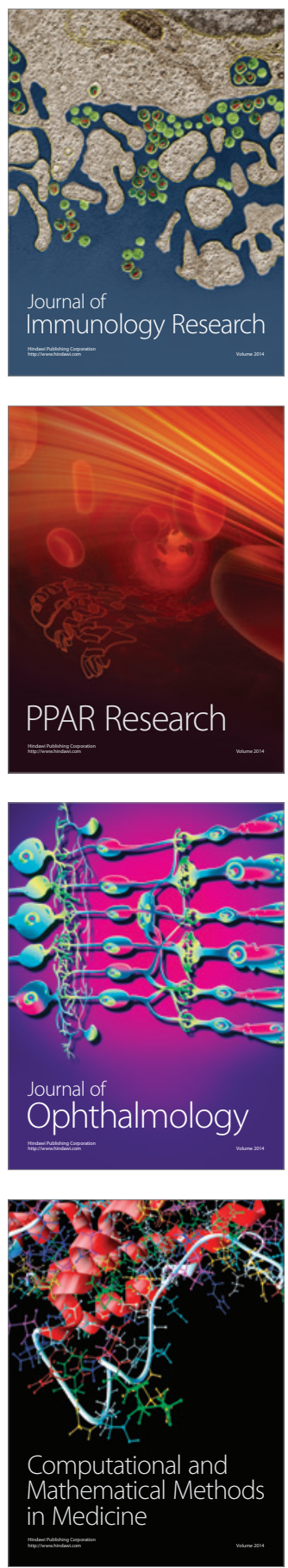

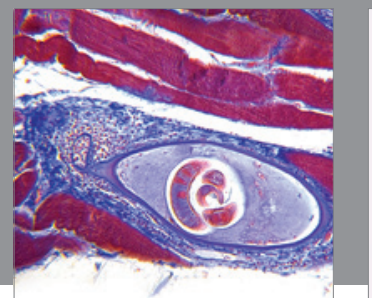

Gastroenterology

Research and Practice
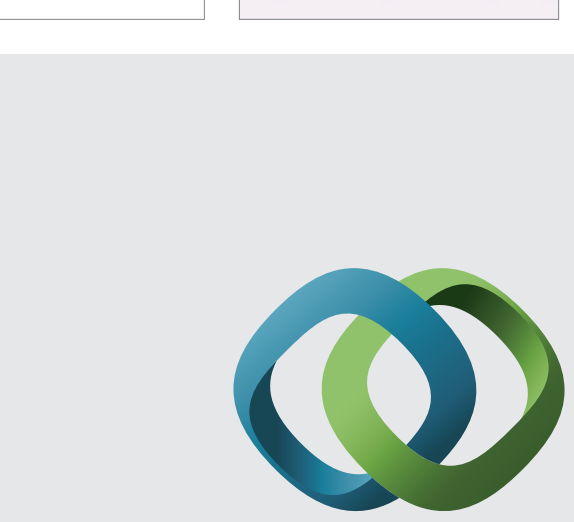

\section{Hindawi}

Submit your manuscripts at

http://www.hindawi.com
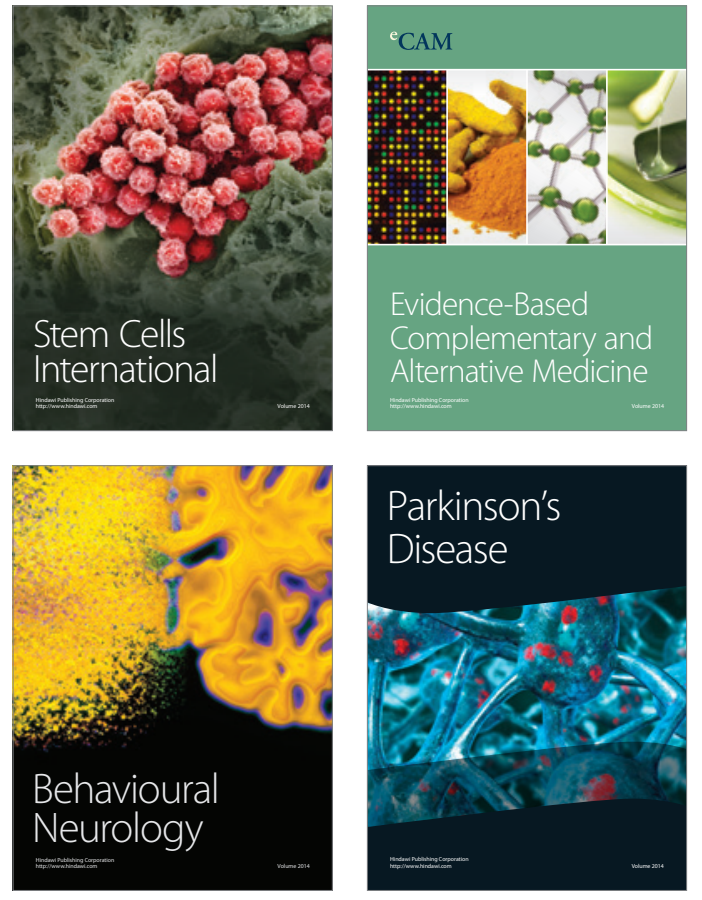
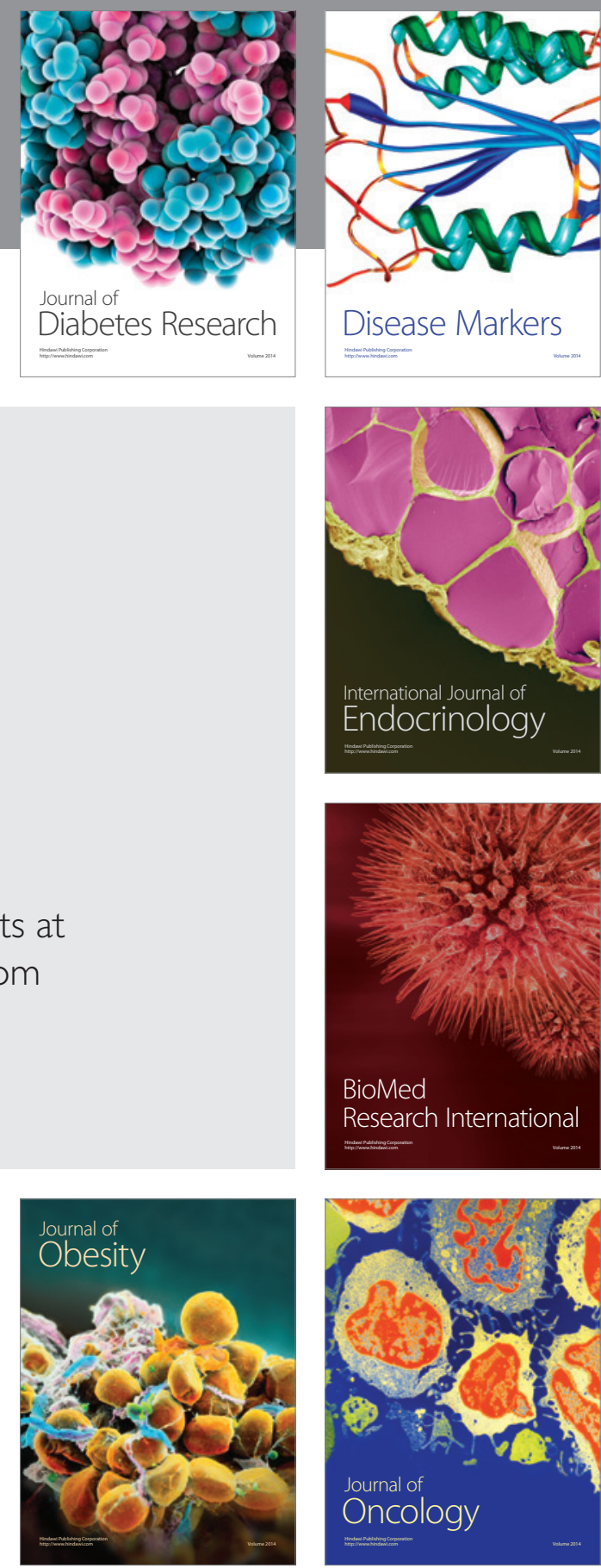

Disease Markers
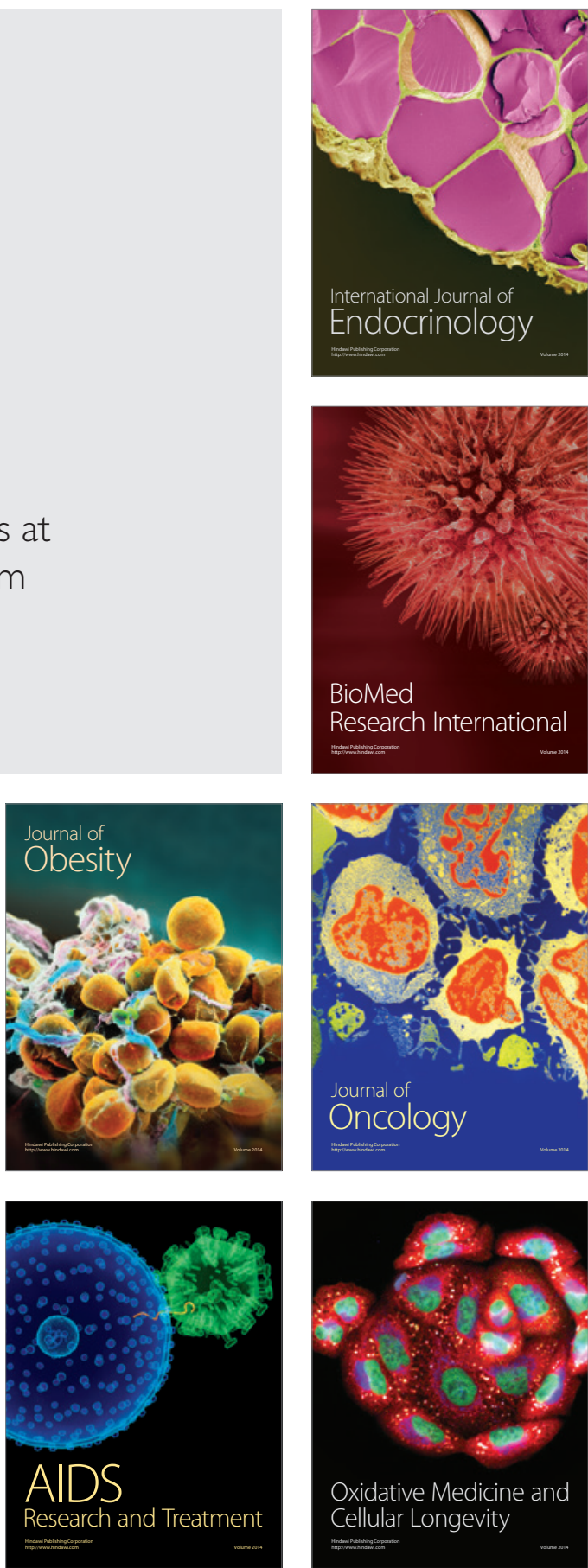